\title{
LA CIUDAD IDEAL EN LA ODISEA DE NIKOS KAZANTZAKIS
}

\author{
Helena González Vaquerizo
}

Universidad Autónoma de Madrid. España

Resumen: este artículo estudia la construcción de una ciudad ideal en la Odisea de Nikos Kazantzakis, poema épico del siglo XX que reescribe y continúa el de Homero, y lo hace prestando atención a los modelos de la literatura utópica. En el canto XV de esta nueva Odisea y tras un largo peregrinaje por el desierto, el héroe se dispone a erigir una ciudad ideal, más justa, más igualitaria, donde la multitud de hombres que lo sigue alcance y supere su destino humano. El mismo día de su inauguración la gran obra será destruida por un terremoto y el héroe reemprenderá su camino en solitario. En la configuración de la sociedad utópica fracasada que propone Kazantzakis toman parte como modelos las ciudades ideales de Platón y Tomás Moro e influyen de manera decisiva el pensamiento nietzscheano, el contexto sociocultural y las circunstancias históricas del siglo XX.

Palabras clave: ciudad ideal, literatura utópica, Odisea, Kazantzakis, siglo XX.

\section{THE IDEAL CITY IN NIKOS KAZANTZAKIS' ODYSSEY}

Abstract: this paper approaches the construction of an ideal city in Nikos Kazantzakis' Odyssey, a $20^{\text {th }}$ century epic poem which rewrites and continues that of Homer. In doing so it focuses on utopian literature patterns. In the XV book of this Odyssey and after a long way through the desert, the hero is about to build an ideal city, more righteous, more equal, where the crowd of people following him can reach and overpass its human destiny. On its very opening date, the great work will be destroyed by an earthquake and the hero will have to start his way on his own again. In the configuration of the failed utopian society which Kazantzakis' proposes the models taken from the ideal cities of Plato and Thomas More, as well as the nietzscheanian thinking, the sociocultural context and the historic circumstances of the $20^{\text {th }}$ century play a determinant role.

Key Words: ideal city, utopian literature, Odyssey, Kazantzakis, 20th century.

Recibido: 19.12.12 - Aceptado: 5.03 .13 
Correspondencia: Helena González VAquerizo. E-mail: helena.gonzalez@uam.es Dept. Filología Clásica, Módulo III, Despacho 3.02., Facultad de Filosofía y Letras. Universidad Autónoma de Madrid. España

\section{Introducción: Nikos Kazantzakis y su Odisea}

$\mathrm{N}$ ikos Kazantzakis (1883-1957), novelista, poeta y dramaturgo griego, cretense y africano, como a él le gustaba decirse, dedicó doce años a la composición de su monumental Odisea (1938), poema épico de 33.333 versos, que continúa y rescribe el de Homero ${ }^{1}$. Se trata de una obra compleja (cf. Introducciones de Didier 1975 y Friar 1958a y b), tanto por la amplitud y el calado filosófico de los temas que trata o la variada procedencia de los motivos que incluye, como por cuestiones formales, tales como la métrica o las características de su lengua (Giakoumaki 1982). La obra es, además, una suerte de biografía espiritual del propio Kazantzakis (Vrettakos 1957, Prevelakis 1958, Prifti 1977, Friar 1979)², quien puso en ella sus mayores esfuerzos y esperanzas, considerándola su Obra por excelencia dentro de una ingente producción literaria ${ }^{3}$. A pesar de ello, en el momento de su publicación la Odisea "cayó como un meteorito sobre las letras griegas» (Beaton 2009: 31), recibió numerosas críticas (Avgeris 1939, Paraschos 1939, Rotas 1943) y malas interpretaciones, que fueron contestadas por el autor con poco éxito ${ }^{4}$. Solo cuando la obra fuera magistralmente traducida al inglés por Kimon Friar en

${ }^{1}$ La presencia de Homero en el poema de Kazantzakis y la figura del héroe Odiseo han sido objeto de análisis pormenorizado por Bretschneider 2007 y Castillo Didier 2007, aunque los primeros trabajos importantes sobre la cuestión son los de Stanford 1954 y 1958. Otras referencias al tema son Lacarriere 1972, que describió la obra como "una Odisea de nuestros tiempos", Stamatiou 1983, que realizó una Tesis doctoral en torno a la relación de Kazantzakis con los antiguos, o Bernardes 2009, que ha estudiado el poema como un palimpsesto del viaje homérico.

${ }^{2}$ Sobre la vida de Nikos Kazantzakis, así como su obra, hay una detallada cronología en inglés y griego en la página web del Museo de Creta (www.historicalmuseum.gr/kazantzakis), así como una abundante bibliografía: Alexiou 1966, Bidal Baudier 1974, Janiuad-Lust 1970, Kazantzaki 1977, Prevelakis 1984.

${ }^{3}$ Estudios generales sobre el autor, su pensamiento y obras pueden encontrarse en Friar 1959, Bien 1972, Omatos (ed.) 1999, Núñez Esteban 1997, Wilson \& Dossor 1999, Stassinakis 1998; bibliografías del autor en griego, inglés y espańol en Katsimbalis 1958, Bien 1974, Quiroz Pizarro 1997, respectivamente.

${ }^{4}$ Véase la polémica mantenida entre Laourdas 1943a y b y Kazantzakis 1943. 
1958 y Stanford le dedicara un amplio capítulo en su The Ulysses Theme (1959), empezaría a recibir la atención que merecía 5 .

El poema comienza allí donde terminara el de Homero: Odiseo ha matado a los pretendientes, se ha reencontrado con esposa, patria e hijo. Lo que sucede a continuación parece en nuestros días la consecuencia inevitable de la interpretación que se ha dado a la figura de Odiseo a lo largo de la tradición y hasta hoy. Pues, en seguida, el gran viajero se da cuenta de que no puede ya quedarse en Ítaca (cantos I-II) como pastor de un pueblo hacia el que no siente apego, sino que debe hacerse de nuevo a la mar, recorrer un camino siempre ascendente en el que se va despojando de todas las formas de la muerte -que identifica con el sedentarismo y que encarnan las figuras de la mujer y el hijo, la imagen de la patria, así como el orden establecido y los dogmas religiosos- hasta agotar todas las experiencias y ser de verdad en el día de su muerte Nadie.

El nuevo periplo le lleva a Esparta (cantos III-IV), donde rapta a Helena, después a Creta (cantos V-VIII), donde destruirá la vieja civilización decadente, y por fin al continente africano. En Egipto se unirá a la revolución socialista contra el faraón (cantos IX-XI) y conducirá al pueblo hambriento como un Moisés por el desierto. Si hasta este momento nos encontramos aproximadamente en los años posteriores a la Guerra de Troya (siglo XII a. C.), a partir de este momento el relato prescinde de referencias temporales y las geográficas se van haciendo más y más imprecisas, tanto, que el héroe recorre la historia de la humanidad para encontrarse al final su viejo perro Argos (XXI, 182).

En África el héroe y sus compañeros no van a encontrar a las seductoras Sirenas, ni a la bruja Circe ni a la ninfa Calipso. Por el contrario, las tentaciones del hombre moderno estarán simbolizadas por tentativas políticas, como la construcción de una "ciudad ideal» (canto XV) ascéticos (cantos XII y XIV, XVI-XXVII), e intelectuales, véanse las prometedoras doctrinas de personajes inspirados en las figuras de Buda, Homero, Don Quijote o Cristo, con los que Odiseo tropieza en su camino (cantos XVIII-XXI). Finalmente el héroe alcanza las heladas soledades del Polo Sur, donde su espíritu, más que morir, se desvanece como una llama en el aire (canto XXIV).

\footnotetext{
${ }^{5}$ Sobre la pervivencia de Kazantzakis en las letras neohelénicas cf. Castillo Didier 1964, Psychogios (ed.) 2006.

${ }^{6} \mathrm{La}$ denominación del canto XV como la «ciudad ideal (ideal city)» aparece por primera vez en Friar (1958).
} 
Las lecturas que pueden hacerse de la obra son múltiples, así como los puntos de vista desde los que abordarla. En este trabajo nos centramos en el motivo de la ciudad ideal, resultado de una evolución política que conduce al héroe del descrédito en la monarquía, ejemplificado por los episodios en Ítaca y Esparta, a la acción revolucionaria en Creta y Egipto, hasta la decisión de erigirse en fundador y Mesías de una nueva sociedad en África. Del tema se había ocupado KonidariFavi en su Idaniki Politeia (Ciudad Ideal) de 1992. Allí la autora destacaba la relación de las rapsodias previas a la fundación con el funcionamiento del poder y el derecho (Esparta, Creta y Egipto tienen en común su fama de buen gobierno en la Antigüedad, Konidari-Favi 1992: 8). Esta apreciación resulta sumamente interesante para nuestro enfoque, pues más adelante defenderemos que la ciudad ideal que funda Odiseo pertenece a la categoría de proyecto utópico que más se relaciona con la legislación, la Utopía. Por otro lado, Konidari-Favi destaca que con el canto XV Kazantzakis, un abogado de formación (Derecho en Atenas) y filósofo de especialización (Doctorado en París) paga su deuda con Platón, un filósofo interesado en el derecho y la política (Las Leyes, La República) y analiza las semejanzas de los proyectos de ambos autores (Konidari-Favi 1992: 9, 109127). El libro se centra especialmente en el proceso que lleva a un héroe vengador (cantos I-XI) y legislador (cantos XII-XIV) a la fundación de la ciudad, con especial atención a estos últimos cantos, donde tiene lugar la construcción espiritual de la ciudad en la imaginación del héroe y donde los paralelismos con las figuras de Cristo y Moisés son destacados. Nuestro artículo, por el contrario, propone un análisis de las características de la sociedad de Kazantzakis desde el punto de vista de los estudios de la tradición utópica (Kuon 1992, Trousson, 1975, 1995, RamiroAvilés 2000, 2002), que consideramos el marco idóneo para estudiar el canto XV y poner de relieve las motivaciones del autor a la hora de crear una sociedad ideal y su propuesta de reforma de la condición humana para alcanzar sus objetivos.

El proyecto se pone en marcha tras siete días y siete noches de retiro ascético. En ese momento, Odiseo decide fundar una ciudad ideal, cuya construcción ocupa el canto XV del poema. Posee esta características que la emparientan con la República platónica y la Utopía de Moro, al tiempo que es fiel reflejo de las inquietudes y de algunas de las corrientes de pensamiento políticas y filosóficas más destacadas del siglo XX. Para su ciudad el héroe de Kazantzakis adopta como credo una suerte de nihilismo trágico y nietzscheano (Kerenyi 1959), con el que el autor se prefigura como precursor del existencialismo filosófico ${ }^{7}$. La ciudad

\footnotetext{
${ }^{7}$ El drama Comedia. Tragedia en un acto (1909) fue la primera obra de tono existencialista del
} autor, que se adelantó a su tiempo anunciando en ella al Beckett de Esperando a Godot y al Sartre 
que funda está regulada por unas leyes afines al comunismo, un movimiento con el que Kazantzakis inicialmente había simpatizado y que, como a tantos intelectuales de la época, había terminado decepcionando (Savvas 1971-1972, Bien 1989 y 2007). La imagen de dios que ofrece el poema, y muy en concreto este canto, es la de un cristianismo en crisis, un fenómeno que el autor vive de cerca y en el cual, como pensador de su tiempo y apasionado humanista que es, se involucra.

Por último, el origen cretense del autor, que en su infancia conoció las luchas de sus compatriotas por la independencia del imperio otomano, determina toda su obra convirtiéndola en una búsqueda constante de libertad a cualquier precio y arrojando sobre la misma la luz de una mirada que él denominó cretense: «La mirada cretense es la mirada valiente del hombre frente al toro, el ojo que mira sin miedo el miedo" (Kazantzakis [1957] 2007, 481) ${ }^{8}$. Con esta mirada es con la que el héroe emprende el proyecto del canto XV, la construcción de una utopía: la ciudad ideal.

\section{Contexto histórico y composición del canto XV de la Odisea}

La Odisea se escribe entre 1924 y 1938 en un período marcado por sendas Guerras Mundiales, así como por la instauración de regímenes totalitarios, ya fueran de orden fascista, como sucedió en Italia, Alemania y España, ya fueran de orientación marxista, como la revolución soviética.

Kazantzakis fue un hombre controvertido en muchos aspectos y sus afinidades y adhesiones políticas no lo fueron menos. Se mostró ciertamente radical e inconstante en sus declaraciones pero, sobre todo, tuvo una visión propia, independiente y penetrante. Cuando, camino de España en 1936 le preguntaron por su postura ante la Guerra Civil contestó: «No estoy ni a favor ni en contra, como no estoy ni a favor ni en contra de un terremoto" (Kazantzakis [1937] 2002, 146). La guerra le parecía sencillamente inevitable. La lucha entre los contrarios era ley de vida y en el momento crucial en el que percibía que estaba viviendo, cuando una civilización aún no había desaparecido y otra pugnaba por surgir, la guerra era la lógica consecuencia y, además, la única vía de superar las diferencias y alcanzar una síntesis. No es de extrañar entonces que diera salida

de A puerta cerrada (Bidal-Baudier 1986, 164; Lacarriere 1972, 14-15). Eleni Kazantzaki señaló acertadamente que, si esta última no fuera treinta años posterior a la Comedia, los detractores de Kazantzakis hablarían de plagio (Kazantzaki, E. 1977, 56). Para el tema cf. Quiroz Pizarro 1998.

${ }^{8}$ Para el concepto de la mirada cretense cf. Grammatas 1992. 
a sus inquietudes precisamente en una obra épica y que, cuando un estudioso griego (Laourdas 1943a) le preguntara qué sentido tenía escribir una epopeya en nuestros tiempos, él le contestara que a su parecer el siglo XX era una época característicamente épica (Kazantzakis 1943, 1228).

Con todo, en el año 1956 le fue otorgado en Viena el Premio de la Paz. Podría pensarse que el hecho constituye una paradoja, pero la realidad es que Kazantzakis había trabajado toda su vida por la paz, mediante la palabra y mediante la acción. Novelas como Vida y hechos de Alexis Zorbas, Los hermanos enemigos o El capitán Mijalis, escritas en 1943 la primera y en 1953 las segundas, son auténticos alegatos contra la guerra y llamamientos a la hermandad de los pueblos. Pero es que mucho antes, en 1918, el gobierno de Venizelos le había encargado la repatriación a Grecia de sus compatriotas residentes en el Cáucaso. En el recuerdo del escritor este trabajo emularía la marcha de Moisés con los elegidos por el desierto (Éxodo 15:22): «como si fuera un Centauro, y toda esa turbamulta que navegaba conmigo fuera, del cuello para abajo, mi cuerpo» (Kazantzakis [1957] 2007, 425). Esta experiencia se verá claramente reflejada en la Odisea, cuando el héroe conduzca a los desterrados de Egipto por el Sáhara hasta el enclave donde funda su ciudad ideal.

Además de la misión humanitaria en el Cáucaso, entre 1946 y 1947 Kazantzakis sería consejero literario de la UNESCO con el explícito cometido de tender puentes culturales entre Oriente y Occidente y en 1945 ministro sin cartera del gobierno de Sofoulis. Todas estas experiencias atestiguan el compromiso social y político del autor y permiten hablar de una auténtica voluntad de cambiar el mundo. El canto XV de la Odisea no es sino el reflejo de tantos intentos de crear una sociedad mejor, una utopía.

La Odisea fue objeto de siete revisiones entre 1924 y 1938 . El canto XV, el de la construcción de la ciudad ideal, fue compuesto por Kazantzakis inmediatamente después de ser invitado oficialmente a Moscú en 1927 para la conmemoración del décimo aniversario de la revolución y modificado en más de una ocasión a partir de 1929, momento en que empiezan las purgas internas en el partido y el ejército rusos, para reflejar el deterioro que la imagen de la URSS fue sufriendo en el autor. No sabemos si, en el caso de haber sido otras las impresiones que Kazantzakis recibiera en este viaje, hubiera sido también otro el destino de su ciudad ideal. Lo cierto es que en el momento de la fiesta de inauguración de la construcción (canto XVI) se produce una serie de prodigios y la ciudad queda completamente destruida por un desastre natural. 
La ciudad ideal de Kazantzakis tiene así mucho de eutopía, pues es el sueño de un mundo ideal y mejor, pero también de distopía y pesadilla del siglo XX, en tanto que refleja las consecuencias de las guerras y los totalitarismos y advierte de la dificultad de que el hombre alcance a llevar a cabo con éxito sus grandes ideas. Sin embargo, su mensaje es el de que el fracaso en todos y cada uno de sus proyectos no ha de llevar al hombre a la desesperación, sino a la aceptación de que el único logro posible para el espíritu es la propia lucha. Esta idea es, quizá, el leit motiv de toda la vida y obra del cretense.

\section{El canto XV de la Odisea como proyecto utópico}

Vamos a analizar a continuación el canto XV de la Odisea como proyecto utópico, para lo cual habremos de detenernos primero en las características del género de la utopía.

La utopía tiene como elemento material la discusión acerca de la mejor forma de gobierno y, en este sentido, comparte el objetivo del ensayo político. Pero en la obra utópica, a diferencia del ensayo político, no encontramos tanto la descripción detallada de un sistema político ideal como su puesta en funcionamiento. Esta cualidad da el sentido de utopía a la obra y la diferencia del programa político que, no obstante, contiene. La utopía, como género, es así perfectamente diferenciable de la reflexión política, porque es una creación eminentemente literaria, que no adquiere su significado sino a través de lo literario, cuando una sociedad utópica es descrita como existente. Se habla por ello de la "primacía de lo literario» (Kuon 1992, 42-49) en el proyecto utópico.

Dos obras de Platón ilustran la diferencia entre la reflexión política y la utopía: la República plantea un proyecto político, un modelo de sociedad, pero no describe su puesta en funcionamiento. En el Timeo, en cambio, Platón sueńa con la utopía: «Quizá queráis escuchar ahora lo que me sucede con la continuación de la república que hemos descrito. Creo que lo que me pasa es algo así como si alguien, después de observar bellos animales, ya sea pintados en un cuadro o realmente vivos pero en descanso, fuera asaltado por el deseo de verlos moverse y hacer en un certamen, algo de lo que parece corresponder a sus cuerpos» (Plat. Tim. 19b).

Es sabido que Platón trató de poner en práctica su modelo de sociedad ideal junto a su amigo Dión en la corte siracusana de Dionisio I y también que 
fracasó. La utopía no lo es porque sea inviable, de hecho, no todos los intentos de llevar a la práctica las utopías han fracasado y la confianza de unos pocos en otros mundos posibles ha contribuido a la mejora de este para la mayoría, sino porque desde el principio fue concebida como una construcción literaria más encaminada a retratar una sociedad y sus problemas a través de la ficción, que a hacerse realidad y constituir el fundamento de sociedades nuevas.

Una consecuencia de la literariedad de las construcciones ideales es la descripción que de ellas hacen los autores como algo presente y llevado a la práctica, antes que como un esquema teórico. Para hablar de utopía hay que «verlos moverse» como decía Platón. El canto XV de la Odisea, donde asistimos a la creación material y espiritual de la ciudad, y en el que el autor pone en juego todo tipo de recursos literarios para hacernos presente esa construcción ideal, a sus habitantes y su ordenamiento, puede adscribirse a la tradición de la literatura utópica. Ningún obstáculo supone que la Odisea pertenezca al género épico, toda vez que se trata de un género narrativo y es precisamente el otro gran género narrativo, la novela, la forma que se considera más apta para el proyecto utópico (Trousson 1995, 43). He aquí algunos ejemplos de cómo se despliega la ciudad ideal de la Odisea:

«Leyes ascendían y mandatos y órdenes y también esperanzas y azules puertas misteriosas para que Caronte entre y salga.

(Kaz. Od. XV, 570-571, Trad. M. Castillo Didier)

“¡Oh ciudadela mía, broquel de mi Dios, carne de mi pensamiento!

en tres pisos te levantas de la tierra, como mi corazón:

piedras y barro son tus pies, bien ensambladas;

leyes grabadas y mandamientos en tu inclemente pecho;

¡y tu cima invisible es un grito que en el espacio vacío se pierde!"»

(Kaz. Od. XV, 1240-1246)

A pesar de ser un proyecto literario más o menos irrealizable, toda utopía tiene por objeto y función transformar la realidad. La sociedad que rodea al autor necesita, a su juicio, ser reformada. Él detectará sus defectos y tratará de compensarlos proponiendo las soluciones y reformas apropiadas. Ejercerá una crítica, planteará una mirada alternativa al presente. Si lo que hace es advertir de las fatales consecuencias de un cierto modelo vigente o que hacia el que la sociedad parece encaminarse, su obra será una distopía. Si retrata el ideal a alcanzar, una eutopía. En cualquier caso, lo característico de las obras utópicas es 
ejercer una función de cambio con respecto a la sociedad real. Como trataremos de poner de manifiesto en las siguientes páginas la ciudad ideal del canto XV constituye, precisamente porque resulta destruida, tanto una crítica efectiva como un proyecto viable de reforma de la sociedad a partir de la modificación de la propia condición humana.

\section{La sociedad ideal del canto XV}

Las características concretas de la sociedad ideal del canto XV de la nueva Odisea pueden estudiarse teniendo como referencia otras utopías literarias conocidas y las formas en que estas abordan el cambio social.

En la literatura utópica existen, a juicio de los especialistas, cinco modelos de sociedad ideal (Ramiro-Avilés 2000, 33-47): Abundantia, cuyo arquetipo es la tierra de Jauja, Naturalia, una suerte de Arcadia feliz, Moralia, la república moral regida por normas éticas, Millennium, propiciada por la intervención divina, y Utopía, aquí en el uso restringido del término, que designa un modelo particular de sociedad ideal especialmente vinculada con el derecho y la legalidad. En Utopía «no se presenta una variante del paraíso como las surtidas por varias religiones, sino la descripción minuciosa de un nuevo orden político; no se muestra una tierra rescatada de los males por decisión divina, sino por el empeño de la voluntad humana, y los males evitados no son los metafísicamente necesarios, propios de nuestra condición y que hallan curso también en Utopía (la muerte, la enfermedad, la vejez, el desamor, la guerra, la traición...), sino los daños sociales provocados por una institución aciaga: la propiedad privada y su vehículo principal, el dinero, como medida de todo lo valioso" (Savater 1999, 11).

Si hemos recogido esta extensa cita es porque, aunque no es nuestra intención tipificar el canto XV de la nueva Odisea dentro de un modelo concreto, es con el de Utopía con el que más similitudes guarda. Solo en este modelo, como en la ciudad estado de Odiseo, juega un papel tan fundamental el derecho, pues se aceptan las deficiencias en el hombre y en el entorno (incluso en la divinidad en el caso que nos ocupa), las cuales se contienen mediante sanciones y controles formales (Trousson 1995, 33) y solo en este modelo juega un papel tan determinante la voluntad del hombre. No obstante, el proyecto utópico de Kazantzakis comparte aspectos de otros modelos, posee, por ejemplo, unas normas de comportamiento (Moralia), que le han sido a Odiseo inspiradas por la divinidad en su retiro (Millenium) y que se fundamentan en los mecanismos de selección de la naturaleza (Naturalia). 
En los siguientes apartados vamos a analizar cómo el canto XV soluciona de manera particular las cuestiones que toda la literatura utópica se plantea y a profundizar en su significado: cuestiones relativas a la naturaleza humana, el entorno natural, la vida del hombre en sociedad, la intervención del hombre y la divinidad en la construcción de la ciudad y el derecho. Al mismo tiempo, haremos referencia, siempre que sea posible, a las posibles fuentes e influencias de otras «ciudades ideales» en esta rareza africana de un héroe épico del siglo XX.

\section{a) La naturaleza humana}

Ya hemos adelantado que, en la Europa que le tocó vivir a Kazantzakis, la imagen ideal del ser humano que él se había formado nunca pudo verse correspondida con la realidad. Este desengaño provocó en él una frustración y aislamiento progresivos. De modo que su propuesta compensatoria ante las taras de la sociedad partió de una modificación de la condición humana. El cambio había de orientarse hacia la sublimación de las capacidades del hombre, en las cuales el autor nunca perdería la fe, y basarse en la constante única de la superación, que formularía en el siguiente imperativo:

"Yo escucho sólo un grito, y éste me basta y me sobra:

¡Sigue siempre, sin preguntar, al alma mejor que tú!»

(Kaz. Od. XV, 975-976).

El héroe pide a sus discípulos, y el poema a sus lectores, que se conviertan en una suerte de superhombres, conscientes y responsables de su deber para consigo mismos, que se esfuercen diariamente por sobrepasar los límites que la antigua divinidad les había impuesto. Ya no sirven las viejas virtudes, son precisas otras nuevas.

La coincidencia de estos principios con los de Nietzsche no es casual, dado que Kazantzakis fue un gran admirador y estudioso del filósofo alemán desde su juventud. Como afirma Kimon Friar, «innumerables sentencias del Zaratustra pueden explicar diferentes partes de la Odisea de Kazantzakis: Vivid peligrosamente. Levantad vuestras ciudades cerca del Vesubio. Enviad vuestros navíos a mares inexplorables. Vivid en guerra» (Friar 1958, 21). A partir de estas ideas, que ya había plasmado en una obra tan breve como fundamental para entender su pensamiento y muy especialmente el poema que nos ocupa, su credo lírico y filosófico, la Ascética $(1922)^{8}$, Kazantzakis da forma a su propio mito:

${ }^{8}$ Laourdas (1943a, 4) ya había señalado que la Odisea de Kazantzakis era su Ascética en forma de obra de arte, pero fue Izzet quien acunó para la epopeya la acertada definición de «transposición 
Odiseo se arriesga, levanta una ciudad destinada a hundirse, viaja a los confines del mundo, destruye civilizaciones. Todo lo hace sin afán de recompensa, con la única meta de proseguir el ascenso. El programa de ascesis propuesto en su credo es llevado a cabo por el héroe en el canto XIV (cf. Konidari-Favi 1992: 90-99) y su ideario aplicado en la constitución de la ciudad.

\section{b) El entorno natural}

La ciudad ideal se construye en las llanuras africanas, en una seca meseta donde, lleno de nudos, florece un peral silvestre (Kaz. Od. XV, 213-214). Su localización exacta viene determinada por los augurios del vuelo de los pájaros (338) y la dirección tomada por las flechas que a tal efecto dispara Odiseo (429). También se realiza el sacrificio de seis gallos y seis gallinas, en irónico recuerdo de los doce dioses olímpicos (450-477), para consagrar los cimientos de una ciudad levantada «en la tierra estéril» (518).

A estas alturas de la obra ya el lector de la nueva Odisea tiene muy claro que se encuentra ante una inversión del poema homérico, por eso la impresión más inmediata que recibe al comparar los modelos de sociedad ideal que ambas obras proponen es que se trata de esquemas radicalmente opuestos. En Homero encontrábamos la detallada descripción de una sociedad ideal, la de los feacios, cuyos jefes «Se sentaban allí de costumbre [...] / a beber y a comer, pues jamás les faltaba» (Hom. Od. VII, 98-99) y en las ramas de cuyos árboles «jamás falta el fruto ni llega a extinguirse, / que es perenne en verano e invierno» (117118). Los feacios, habitantes de un mundo donde los bienes nunca se agotan, se corresponden con el modelo de Abundantia. Muy al contrario, en Kazantzakis nada es dado, sino todo trabajado por y para el hombre, que ha de obrar como el peral, que florece con lo poco que la Moira le ha dado (agua, tierra y piedras), en lucha constante con los elementos. El duro entorno natural, lejos de ser un obstáculo para la realización del ideal, nos parece cuidadosamente elegido por Kazantzakis para representar el único medio donde las capacidades del hombre pueden desarrollarse al máximo: un medio exigente, una climatología despiadada, un contexto, en fin, de lucha por la supervivencia y la superación.

artística» de la Ascética: «Kazantzakis ha tratado, en la Ascética, de revivir profundamente en sí mismo todos los ciclos de la marcha del hombre sobre la tierra. Lo ha hecho aquí de forma abstracta. [...] Más tarde, en la Odisea, lo hará creando una obra de arte» (Izzet 1964: 34950). Y el mismo Kazantzakis diría años más tarde: «¿Qué quise expresar en la Odisea? La única respuesta es: lo mismo que expresé en la Ascética, mi Credo» (Kazantzakis 1977: 3-23). Para la Ascética cf. Tsiropoulos 1986. 


\section{c) La vida del hombre en sociedad}

Como en la República platónica, también en la anónima ciudad estado de la Odisea la población se divide en tres clases de ciudadanos: los «buenos trabajadores», que laboran la tierra, el mar y el aire, los «lanceros», que guardan la ciudad, y "en la cima, el fruto de todo el combate, los combatientes de espíritu» (Kaz. Od. XV, 540-544). Pese a que no hay un desarrollo explícito de sus funciones, estas tres clases de hombres parecen corresponderse respectivamente con los artesanos, guardianes y gobernantes platónicos (Plat. Rep. VI).

La hostilidad del entorno natural determina un modelo de sociedad colectiva donde el reparto de tareas y bienes se impone. Un régimen de tipo comunista no muy diferente del de la República platónica (V, 462a):

«En todo, en tierra, en herramientas, Dios es el único dueño;

derrumbaron las almas los vallados, aquí lo mío y lo tuyo, y todo labraban fraternales, y todo repartían fraternalmente».

(Kaz. Od. XV, 1096-1098)

En la sociedad que propone Odiseo la propiedad privada y el matrimonio son ilegales; el amor y el sexo, libres.

"iNo quiere Dios hogares separados, ni puertas entrabadas!

quien tiene mujer e hijo y animales en una casa cercada,

encierra a la virtud ociosa y asfixia a la deidad;

y el mundo no penetra en el umbral de su puerta.

En la ciudad de nuestro Conductor, no hay hogares separados;

quien quiera unirse en amor con una nińa, que la tome,

y que vayan a lo hondo de la selva a gozar del gran rayo,

¡y que de nuevo se separen a la aurora, antes que el placer decaiga!»

(Kaz. Od. XV, 550-557)

Los ancianos y ciudadanos inútiles viven separados hasta que se les deja morir. Este pensamiento antigeriátrico va contra el pensamiento clásico, que nosotros hemos heredado a través del cristianismo, pero concuerda con ciertas corrientes del siglo XX.

«Sólo los viejos y las ancianas que vivan separados, descrédito de la humanidad, y que mueran todos luego, para que vuelvan a la tierra, para que coman y beban las raíces de la raza, y que los nietos [florezcan».

(Kaz. Od. XV, 558-560) 
Los niños, por representar el futuro y ser de vital importancia, son criados en común y educados por la comunidad.

«En un lugar aparte, los niños jugarán y crecerán,

lejos de los padres de-pesada-sombra, no vayan a marchitarse sus corazones;»

(Kaz. Od. XV, 561-562)

La fuente clásica para este modelo es, de nuevo, Platón (Rep.V, 457e) y, junto a él, la descripción de la sociedad espartana hecha por Jenofonte en la República de los Lacedemonios. El sentido de tantas medidas represoras desde nuestra perspectiva de la libertad individual, de tan poca compasión con los elementos más débiles, no es otro que el que venimos reiterando a lo largo de estas páginas: que el hombre debe, según el modelo propuesto por Kazantzakis, sacrificar todo a la liberación de su espíritu.

\section{d) La intervención del hombre y la divinidad}

La intervención del hombre en la construcción de esta sociedad es crucial, porque en él reside la clave del éxito. El objetivo del proyecto, por encima de la culminación de la construcción de la ciudad, es la modificación radical de la naturaleza humana en el proceso, su superación. Con este fin Odiseo se esfuerza pacientemente en instruir al pueblo y hacerle comprender la naturaleza terrible de su nuevo dios (Kaz. Od. XV, 513-514). Y es que la divinidad es una fuerza en la sombra, un grito que nace del interior de cada hombre y si todo el peso de la construcción de la ciudad recae sobre el individuo, es porque este puede y debe erigirse en sostén del dios que en él habita.

No es una utopía mileniarista al uso la de Kazantzakis. La divinidad juega un papel fundamental inspirando a Odiseo el modelo de su ciudad, pero esta no es una alternativa al paraíso ultraterrenal, un refugio o vía de escape donde todo es mejor y más fácil que en la realidad, como ocurre tradicionalmente en Millenium. Si hay un paraíso terrenal este reside en la satisfacción por el propio esfuerzo y en la dura exigencia de la superación individual, sin ánimo de recompensa. He aquí, a modo de ejmplo, lo que el dios le dice a Odiseo, cuando este asciende como Moisés a la montaña para recibir las Tablas:

«Aprende a obedecer; solo se considera libre el alma que sigue sumisamente y goza de un objetivo más alto.

y aprende a mandar; en esta tierra solo el que sabe dar duras órdenes se considera puño y boca míos. 
¿Cuál es mi camino? La subida más ardua e interminable.

Y di: yo solo he de salvar la tierra entera.

¿Dónde vamos? ¿Alguna vez venceremos? ¡No preguntes, combate!»

(Kaz. Od. XV, 817-823)

Junto al deber individual, es fundamental la colaboración de todos los miembros de la sociedad. El proyecto ideal está abierto a todos, pero no es sino para los más fuertes, de ahí que quien quiera pueda abandonarlo:

«El que de vosotros, compañeros míos, pueda soportarlo, que se quede; mas los que piden en el mundo un Dios compasivo e inmortal, que al punto se levanten con sus familias y enseres y que partan»

(Kaz. Od. XV, 921-923)

Se trata de un camino arduo y ascendente cuyas recompensas no resultan evidentes, tanto más cuanto que en él ese Dios que pide la disposición ciega a la lucha y que, recordemos, desde la irrupción de Nietzsche ha muerto, está tan necesitado de los hombres como estos de él:

«Tiembla, hermanos, el Dios, y gime en nuestros pechos: “AAuxilio!”

(Kaz. Od. XV, 900)

Hermanos, no es todopoderoso; su sangre corre, tropieza por la tierra, $\mathrm{y}$ Caronte le sigue la pisada.

(Kaz. Od. XV, 910-911)

“¡Sangre, sudor y fuego, tierra y agua, eso es mi Dios!

no es pensamiento inmortal ni un pájaro del aire, sino que es carne mortal como la de nosotros, un cerebro trémulo que casi se apaga, corazón intranquilo y obstinado que tiembla como el del hombre; ¡y no sabe de dónde partió y hacia dónde se dirige!"»

(Kaz. Od. XV, 912-920)

El desvalido dios de la Odisea es el mismo de la Ascética, no en vano subtitulada Salvatores Dei.

\section{d)La ley fundacional}

En cuanto a sus fundamentos legales, el de la Odisea es un modelo de sociedad ideal que se acerca al de Naturalia, porque propone el regreso a las leyes de la naturaleza. No obstante, en su aplicación el resultado difiere radicalmente de la Arcadia feliz del buen salvaje, y lo que encontramos es una 
ciudad sometida a la ley de la naturaleza en su más cruda formulación: la selectiva ley del más fuerte.

El héroe encuentra la ley fundacional de su ciudad ideal cuando ve una bandada de termitas que se aparean en el aire. Tan pronto como los machos han cumplido su única función, caen muertos a tierra donde son devorados inmediatamente por pájaros, escarabajos, escorpiones y serpientes. Odiseo acepta esto como una despiadada ley de necesidad y supervivencia en la naturaleza.

El hombre, como la cruel naturaleza que se le ofrece como ejemplo de ley, no es bueno ni malo, pero puede ser mejor. La superación de la condición humana solo puede alcanzarse mediante la sumisión a una ley «más grande, más fecunda, depositaria de la virtud / En la cual cimentar su ciudad misteriosa y sobrehumana, a saber:

«Lo que la ciega-gusana madre tierra realiza sin conciencia, justo es que nosotros con ojos bien abiertos, con conocimiento lo queramos; ¡toma ejemplo de Dios, solitario, para gobernar la tierra!»

(Kaz. Od. XV, 601-603)

La asunción de esta ley tiene su correlato en la Utopía de Moro, donde la virtud consiste en vivir según la naturaleza y la eutanasia es defendida (Moro 1977, 91-92). También en la naturaleza se fundamenta la muerte de los ancianos, defendida en el canto XV, a partir del retorno de la materia muerta a la vida: «iAbuelo, tú ya no sirves; baja a la tierra para renovarte!» (Kaz. Od. XV, 1001). En cierto momento Odiseo llega incluso a planear reunir junto al precipicio a todos los ancianos y empujar a los que no sirvan (608 ss.), lo cual nos recuerda, por supuesto, a la controvertida sociedad espartana de la Antigüedad tal y como la describiera Jenofonte. Como consecuencia de estos ideales, la muerte de un anciano jefe no es una ocasión de luto sino de júbilo:

«Justo es que cantemos llenos de alegría al anciano que muere; jadeaba, vacío quedó y ya no sirve, en vano come pan; la carne corrompida que descienda a la tierra, a ese gran taller, ¡y se funda en nuevas y hondas muelas, para poder renovarse! Mas cuando muere un joven sin ramas, que resuene el lamento en las tumbas desoladas, pues sin retorno baja a la tierra una alma grande, ¡y Dios ya pierde para siempre una lanza!»

(Kaz. Od. XV, 1010-1016) 
Estas concepciones morales entroncan con la visión de la muerte que tienen los habitantes de la isla de Utopía de Moro. De ellos cuenta Rafael Hytlodeo que «aunque les duele la enfermedad de todos, no lloran la muerte de nadie a no ser la de aquellos que se van contra su voluntad y poseídos de angustia [...] Por el contrario, nadie llora la muerte de los que fallecieron con ánimo alegre y con santa esperanza» (Moro 1977, 113). La ley de necesidad y supervivencia en la naturaleza es un principio abstracto que comparten ambas sociedades y que se ve aplicado en la práctica en el caso concreto del anciano en la Odisea, porque si el canto XV es, como hemos defendido, una utopía, no solo interesa enunciar la ley, sino mostrar su funcionamiento y sus motivaciones.

Finalmente Odiseo grabará en la dura piedra las leyes de la ciudad en forma de decálogo: (XV, 1161-1176).

\section{3) Conclusiones}

Los utopistas, se ha dicho, "no inventan lo que no hay, sino que enfrentan lo que hay con lo que debería haber» (Savater 1997, 12). Sin embargo, la ciudad ideal del nuevo Odiseo resulta destruida por una catástrofe natural, como si su fundador y sus habitantes se hubieran equivocado, como si de un castigo se tratara. Es llamativo que ya antes de comenzar la construcción de la ciudad Odiseo parezca tener prevista su ruina, pues tras explicar a sus compañeros el diseño trazando el dibujo con su puñal sobre las ascuas del fuego, la deshace con ímpetu (Kaz. Od. XV, 400-417).

Ante la destrucción efectiva de la ciudad, que tiene lugar en el canto XVI, el lector se pregunta si se trata de un castigo por los errores cometidos, lo cual significaría que la intención del autor era una crítica del modelo propuesto (léase del comunismo) o si de simple fatalismo, ya que la ruina viene del lado de la naturaleza. Ocurre como con la Utopía de Moro: al terminar de leer estas obras, no se tiene demasiada certeza sobre las intenciones del autor. Los personajes presentan valores y principios contrapuestos, la utopía resulta autocrítica. Puesto que la ciudad ideal es destruida, ¿era desde el comienzo una distopía?, ¿estaba advirtiendo Kazantzakis de los peligros del totalitarismo estalinista? Es muy posible, dado que el autor, idealista y admirador de los totalitarismos en tanto movimientos genuinamente heroicos y valientes (Bien 2007, 1-16), terminó por desengańarse ante las atrocidades cometidas por los líderes del momento y, gracias a sus viajes a Rusia como corresponsal para un periódico ateniense pudo seguir de cerca la evolución del estalinismo, la cual 
terminó condicionando las sucesivas revisiones que haría de su gran obra, la Odisea, y especialmente del canto XV.

Como consecuencia de estas experiencias, uno de los principios generales del pensamiento de Kazantzakis será el de que «la revolución traicionará sus propios principios tan pronto como sea alcanzada y para que esto no suceda, la ciudad estado de Odiseo es destruida incluso antes de su inauguración oficial» (Bien 1989, 237). Así puede entenderse el gesto inicial de Odiseo al destruir el proyecto trazado sobre el fuego. Por otra parte, para un héroe que había abandonado la seguridad del hogar o la tentación del poder, la ciudad representaba una esperanza y, por tanto, también una trampa en su camino.

Las circunstancias reales empujan a un autor a construir, aunque sea tan solo en la ficción, un mundo mejor, criticando y condenando las taras de una sociedad a la que no ha sabido o querido adaptarse (Trousson 1995, 39). La Odisea muestra que las taras de sociedad radican en la propia condición humana y propone una vía única para mejorarla: el esfuerzo que no espera recompensa. Solo en la tensión de la lucha brilla el hombre, solo entonces exprime al máximo sus capacidades. Una vez alcanzado el objetivo comienza la decadencia, hasta que una nueva revolución vuelve a sacar lo mejor del espíritu. Kazantzakis está buscando el tipo de revolucionario que personificaría algunos años más tarde un personaje como el «Che» Guevara, quien no concebía la lucha revolucionaria sino en el campo de batalla, quien no habría tomado parte del gobierno castrista caso de haber sobrevivido. La lucha por alcanzar la libertad, no su consecución ni el proceso de consolidación de un nuevo sistema político, la victoria sobre los propios miedos y la supresión de toda esperanza. Tales eran los ideales de Kazantzakis y su héroe Odiseo. Uno debe ser muy valiente para enfrentarse al peligro sabiendo que no hay esperanza, para sobreponerse al sufrimiento siendo consciente de que este es inevitable, y para esforzarse en superarse siempre, a pesar de que no le aguarde recompensa alguna. Pero es seguro que, liberado de miedos y esperanzas, el hombre habrá roto todas sus ataduras y será libre, pues solo en la dialéctica de la lucha puede el hombre alcanzar la libertad.

Kazantzakis confía en la superación de la naturaleza humana, no porque crea en la bondad natural de las personas, sino porque, como otros utopistas, cree que "el hombre tiene una maleabilidad casi infinita» (Ramiro-Avilés 2002, 54). La Odisea es así un canto al espíritu humano, a su afán y capacidad de superarse. El canto XV nos ha permitido ver ese ideal y, como ha tratado de mostrar este 
trabajo, lo ha hecho insertándose en el marco de la tradición utópica: su elemento material ha sido la discusión acerca de la mejor forma de gobierno; aunque prima en él lo literario, ejerce una función crítica frente a la sociedad real e imperfecta, y una compensatoria, que corrige sus defectos; hay una transformación radical de la sociedad, terrenal, alternativa al paraíso y al más allá; el contexto histórico y cultural, por fin, ha influido enormemente en la configuración de la sociedad ideal, determinando las soluciones propuestas.

\section{Referencias bibliográficas}

\section{Biografías, bibliografías y obras generales sobre Nikos Kazantzakis}

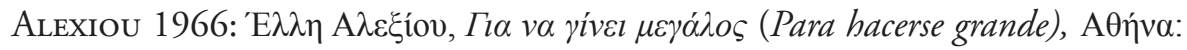
$\Delta \omega$ рıко́

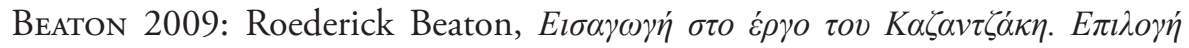

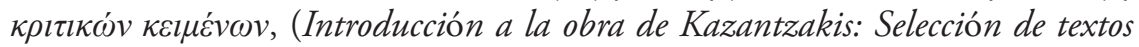

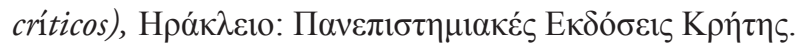

Bidal Baudier 1974: Marie Louise Bidal Baudier, Nikos Kazantzaki: comment l'homme deviene immortel, Paris: Plon.

Bien 1972: Peter Bien, Nikos Kazantzakis, New York: Columbia University Press.

BIEn 1974: Peter Bien, «Nikos Kazantzakis. A checklist of primary and secondary works supplementing the Katsimbalis bibliography», Mantatoforos 5, 7-53.

BIEN 1989 y 2007. Peter Bien, Politics of the Spirit, vol. 1 y 2. Princeton: University Press.

FrIAR 1958: Kimon Friar, Introduction, Nikos Kazantzakis, The Odyssey-A Modern Sequel, New York: Simon \& Schuster.

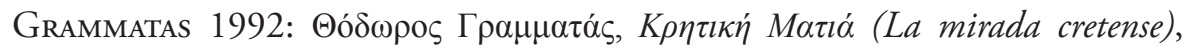
A $\theta \dot{v} v \alpha: \varepsilon \kappa$. А $\varphi \omega v$ To $\lambda i \delta \delta \eta$.

Janiaud-Lust 1970: Colette Janiaud-Lust, Nikos Kazantzakis. Sa vie, son oeuvre (1883-1957), Paris: La Découverte.

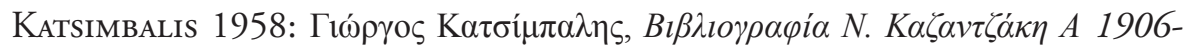

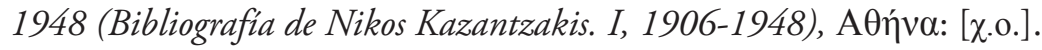

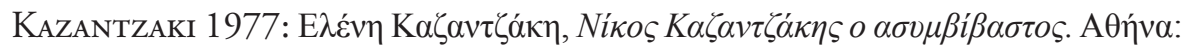

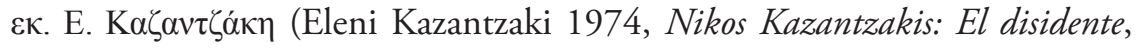
Trad. Josefina Guerrero, Barcelona: Planeta). 


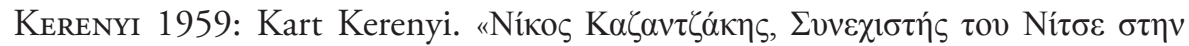

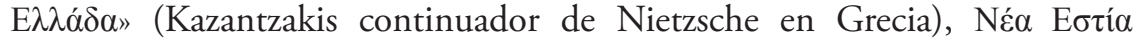
33,779, 42-59.

NúŃEz Esteban 1997: Goyita Núñez Esteban, Nikos Kazantzakis (1883-1957), Madrid: Ediciones del Orto.

Omatos 1999: Olga Omatos (ed.), Tras las huellas de Kazantzakis, Granada: Athos-Pérgamos.

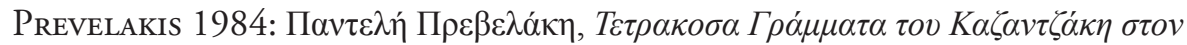

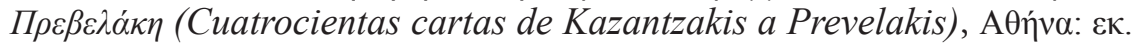
Е. К $\alpha \zeta \alpha \nu \tau \zeta \alpha ́ \kappa \eta$.

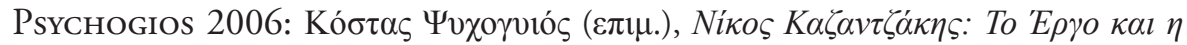

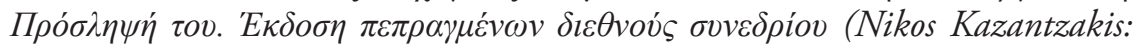

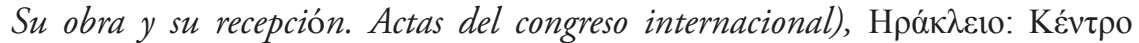

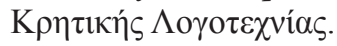

Quiroz Pizarro 1997: Roberto Quiroz Pizarro, Kazantzakis: Cronología y Bibliografía castellana e Iconografía poética, Cuadernos Byzantion Nea Hellas, Santiago (Chile): Centro de Estudios Bizantinos y Neohelénicos.

Quiroz Pizarro 1998: Roberto Quiroz Pizarro, Abismo y fe. Aproximaciones a la Comedia de Kazantzakis, Centro de Estudios Griegos Bizantinos y Neohelénicos, Universidad de Chile, Santiago, Ediciones LOM.

Savvas 1971-1972: Minas Savvas, "Kazantzakis and Marxism», Journal of Modern Literature 2.2, 284-292.

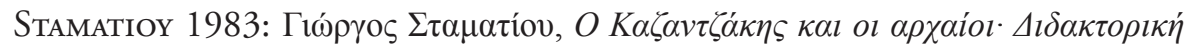

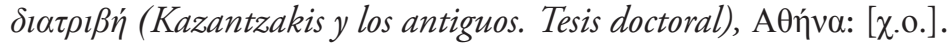

Stassinakis 1998: George Stassinakis, "Nikos Kazantzakis, un pensador de nuestro tiempo»: http://www.apocatastasis.com/nikos-kazantzakis pensador-nuestro-tiempo-george-stassinakis.php\#axzz18ptCQ6u2

Tsiropoulos 1986: Kostas Tsiropoulos, «Introducción», Nikos Kazantzakis 1986, Ascética, Barcelona: Kyklades.

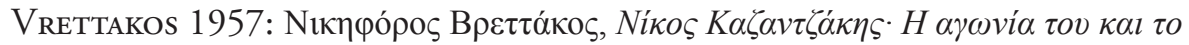

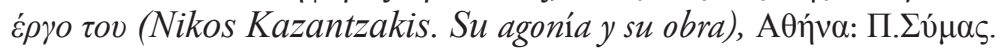

Wilson \& Dossor 1999: Colin Wilson \& Howard F. Dossor Nikos Kazantzakis, Nottingham: Paupers.

\section{Obras de Nikos Kazantzakis}

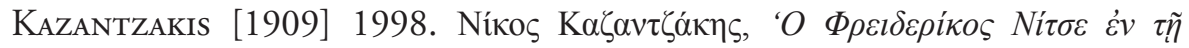

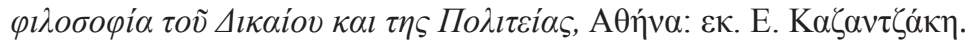




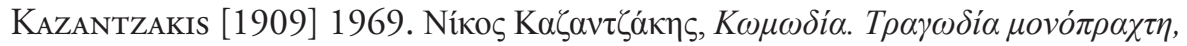
intro. Karl Kerényi, Zurich: ed. Rev. Propilaia.

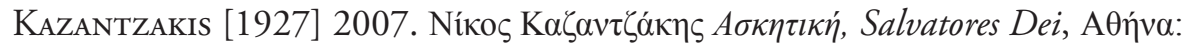

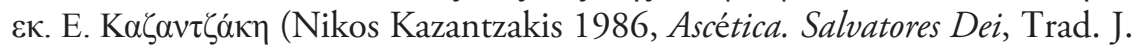
Ruiz, Barcelona: Kyklades).

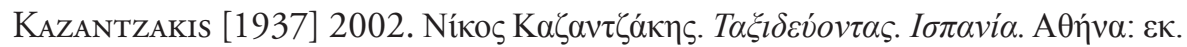

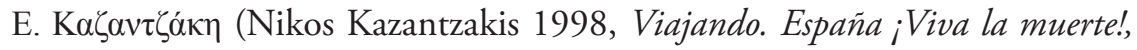
Trad. G. Flores Liera, Madrid: ed. Clásicas).

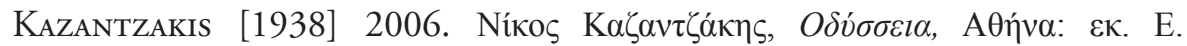

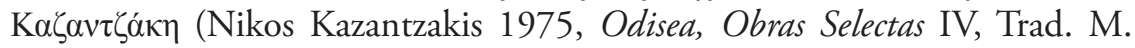
Castillo Didier, Barcelona: Planeta).

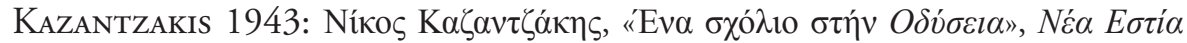

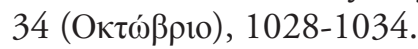

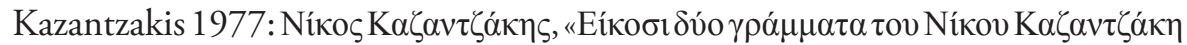

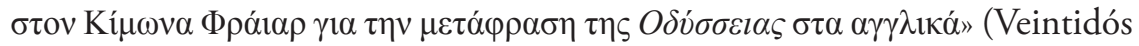
cartas de N. K. a Kimon Friar sobre la traducción de la Odisea al inglés), To $\mu \dot{\varepsilon} \varsigma$ 17, 3-23.

\section{Estudios sobre la Odisea}

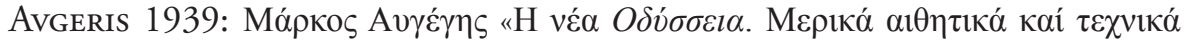

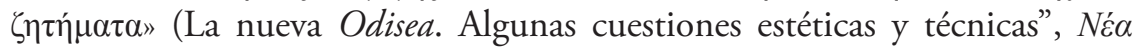

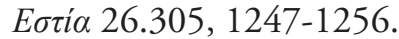

Bernardes 2009: Carolina Bernardes, "A Odisséia de Nikos Kazantzakis: palimpseto da viagem homerica», Texto poético. Revista do GT Teoria do Texto Poético (Anpoll) http://www.textopoetico.org/index.php?option=com_cont ent \&view=article\&id=23\&Itemid=14

Castillo Didier 1964: Miguel Castillo Didier, "Permanencia de Nikos Kazantzakis en las letras neohelénicas: La Odisea», Boletín de la Universidad de Chile 46, 54-63.

Castillo Didier 1975: Miguel Castillo Didier, «Traducción, introducción, notas, resumen en prosa, glosario, bibliografía, post scriptum», Nikos Kazanrzakis 1975, Obras Selectas IV: Odisea, Barcelona: Planeta.

Castillo Didier 2007: Miguel Castillo Didier, La Odisea en la Odisea. Estudios y ensayos sobre la Odisea de Kazantzakis, Santiago (Chile): Centro de Estudios Bizantinos y Neohelénicos «Fotios Malleros».

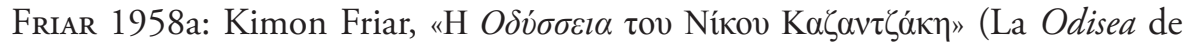

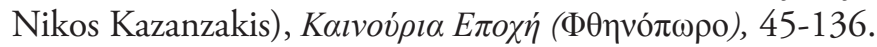


Friar 1958b: Kimon Friar, «Translation into English Verse, Introduction, Synopsis, and Notes», Nikos Kazantzakis 1958, The Odyssey: A Modern Sequel, New York: Simon and Schuster.

FrIAR 1979: Kimon Friar, The Spiritual Odyssey of Nikos Kazantzakis, Minneapolis: North Central Pub. Co.

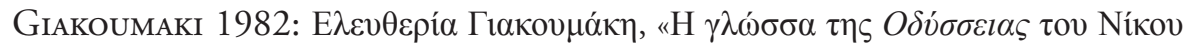

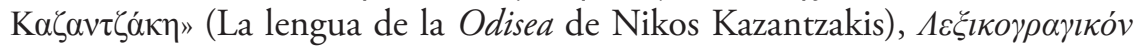
$\Delta \varepsilon \lambda$ tiov $14,143-167$.

IzzeT 1964: Aziz Izzet, «Kazantzaki et l' Odysee», Cahiers du Sud 377, 347-355.

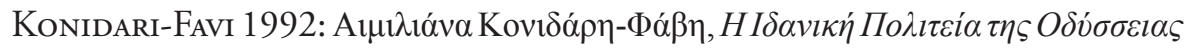

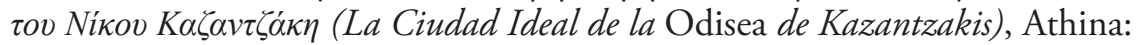
Basileios.

LACARRIERE 1972: Jacques Lacarriere, «Nikos Kazantzakis. Sur les traces d' Ulysse. Chant planétaire, océan poétique: Une Odyssée de notre Temps», Le Monde (28-01-1972), 14-15.

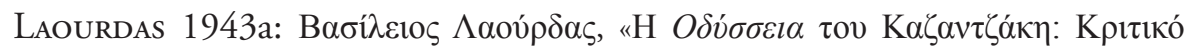

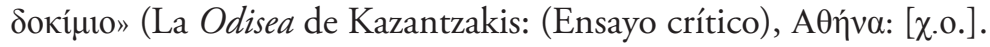

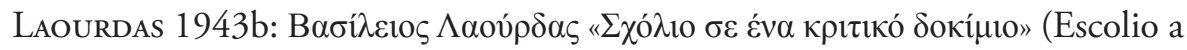

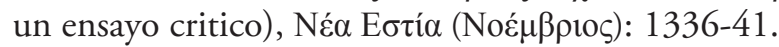

LevitT 1978: Morton P. Levitt, «Kazantzakis' Odyssey: A Modern Rival to Homer", Journal of the Hellenic Diaspora 5.2, 19-45.

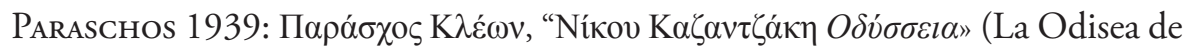

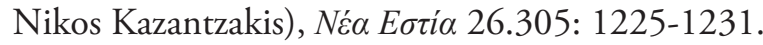

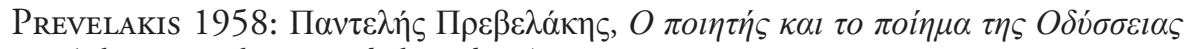

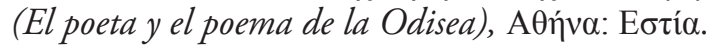

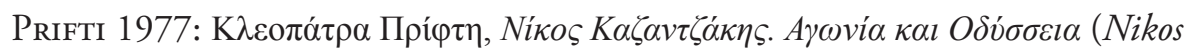

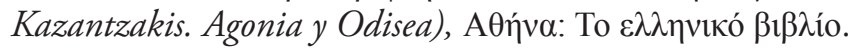

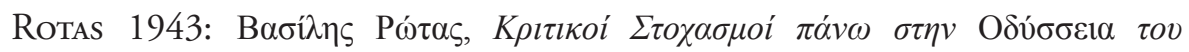

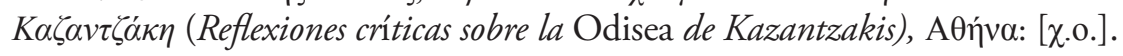

Stanford 1954: William B. Stanford, The Ulysses Theme: A Study on the Adaptability of a Traditional Hero. Oxford: Basil Blackwell.

Stanford 1959: William B. Stanford, «No Rest for Ulysses. From Homer to Kazantzakis», Encounter 13.1, 44-50.

Vougiouka 2010: Athina Vougiouka, «Between Two Regions: Incommensurability of Paradigms in Nikos Kazantzakis's Odyssey», Journal of Modern Greek Studies, 28.1: 115-142. 


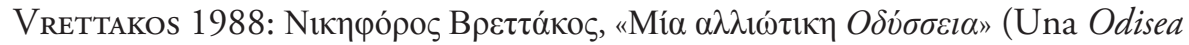
diferente), $\triangle \iota \alpha \beta \dot{\alpha} \zeta \omega 1$ 190, 51-53.

\section{Estudios sobre la tradición utópica}

Kuon 1992. Peter Kuon, «Le primat du lettéraire. Utopie et méthodologie», Nadia Minerva (ed.), Per Una Definizione dell'Utopia, Ravena: Angelo Longo Editore, 42-49.

More [1516] 1986. Thomas More, Utopia, London-New York: Penguin Books (Tomás Moro 1977, Utopia, Trad. J. Mallafré Gavaldá, Barcelona: Planeta).

Nietzsche 1930, Friedrich Nietzsche, Also sprach Zarathustra: ein Buch für alle und keinen, Leipzig: Alfred Kröner (Friedrich Nietzsche 1987, Asi habló Zaratustra, Trad. A. Sánchez Pascual, Madrid: Alianza Editorial).

Ramiro-Avilés 2000: Miguel Ángel Ramiro-Avilés, "Aproximación a los diferentes modelos de sociedad ideal», Qi 3, 33-47.

Ramiro-Avilés 2002: Miguel Ángel Ramiro-Avilés, Utopia y Derecho, Madrid: Marcial Pons.

Savater 1977. Fernando Savater, «Prólogo», Tomás Moro 1977, Utopia, Trad. J. Mallafré Gavaldá, Barcelona: Planeta.

Trousson 1975. Raymond Trousson, Voyages aux pays de nulle part: histoire litteraire de la pensee utopique, Bruxelles: Editions de l'Universite de Bruxelles (Raymond Trousson 1995, Historia de la literatura utópica, Trad. C. Manzano de Frutos, Barcelona: Península).

\section{Autores clásicos}

Homero, Odisea, Trad. J.M. Pabón, Madrid: Gredos 2000.

Platón, República, Trad. C. Eggers Lan, Madrid: Gredos 1992.

Platón, «Timeo», Platón, Diálogos VI, Trad. F. Lisi, Madrid: Gredos 2000.

Jenofonte, «La República de los lacedemonios», Jenofonte, Obras Menores, Trad. O. Guntińas Tuñón, Madrid: Gredos 2000. 